Research Paper

\title{
Biological Characteristics of Foam Cell Formation in Smooth Muscle Cells Derived from Bone Marrow Stem Cells
}

\author{
Pengke Yan ${ }^{1 *}$, Chenglai $\mathrm{Xia}^{1^{*}}$, Caiwen Duan ${ }^{2 *}$, Shihuang $\mathrm{Li}^{3}$, Zhengrong Mei ${ }^{1}$ \\ 1. Department of Pharmacy, The Third Affiliated Hospital of Guangzhou Medical College, Guangzhou 510150, China; \\ 2. Institute of Pharmacology and Pharmacy, Nanhua University, Hengyang, Hunan 421001, China; \\ 3. Chenzhou Fourth People's Hospital, Chenzhou 423000, China. \\ * The first three authors contributed equally to this study.
}

Corresponding author: Pengke Yan,_Tel: +86-20-81292706; Fax: +86-20-81292477; E-mail: yanpk@tom.com

( ) Ivyspring International Publisher. This is an open-access article distributed under the terms of the Creative Commons License (http://creativecommons.org/ licenses/by-nc-nd/3.0/). Reproduction is permitted for personal, noncommercial use, provided that the article is in whole, unmodified, and properly cited.

Received: 2011.04.18; Accepted: 2011.07.27; Published: 2011.08.05

\begin{abstract}
Bone marrow mesenchymal stem cells (BMSC) can differentiate into diverse cell types, including adipogenic, osteogenic, chondrogenic and myogenic lineages. There are lots of BMSC accumulated in atherosclerosis vessels and differentiate into VSMC. However, it is unclear whether VSMC originated from BMSC (BMSC-SMC) could remodel the vessel in new tunica intima or promote the pathogenesis of atherosclerosis. In this study, BMSC were differentiated into VSMC in response to the transforming growth factor $\beta$ (TGF- $\beta$ ) and shown to express a number of VSMC markers, such as $\alpha$-smooth muscle actin (a-SMA) and smooth muscle myosin heavy chain1 (SM-MHC1). BMSC-SMC became foam cells after treatment with $80 \mathrm{mg} / \mathrm{L}$ ox-LDL for 72 hours. Ox-LDL could upregulate scavenger receptor class A (SR-A) but downregulate the ATP-binding cassette transporter A1 (ABCA1) and caveolin-1 protein expression, suggesting that modulating relative protein activity contributes to smooth muscle foam cell formation in BMSC-SMC. Furthermore, we found that BMSC-SMC have some biological characteristics that are similar to VSMC, such as the ability of proliferation and secretion of extracellular matrix, but, at the same time, retain some biological characteristics of BMSC, such as a high level of migration. These results suggest that BMSC-SMC could be induced to foam cells and be involved in the development of atherosclerosis.
\end{abstract}

Key words: Bone marrow mesenchymal stem cells; vascular smooth muscle cells; atherosclerosis; SR-A; ABCA1; caveolin-1

\section{Introduction}

Atherosclerotic cardiovascular disease such as coronary atherosclerosis and stroke remains the leading cause of death all over the world [1, 2]. Various cell types play crucial roles in the destabilization and subsequent rupture or erosion of an atherosclerotic plaque, including apoptosis of foam cells and proliferation of vascular smooth muscle cells (VSMC) at different phases of the disease [3]. Cholesterol accumulation in vascular smooth muscle cells (VSMC) and monocytes/macrophages leads to the formation of lipid-loaded cells, causing a key process of atherosclerosis. It is considered that macrophages taking up ox-LDL could modify the production of cytokines and other factors through oxidative-sensitive signaling pathways, and then initiate and promote atherosclerosis.

Numerous studies have reported that excessive accumulation of vascular smooth muscle cells (VSMC) has a key role in the pathogenesis of vascular diseases. It has been assumed that VSMC derived from the 
outer medial layer migrate, proliferate, and synthesize extracellular matrix components on the luminal side of the vessel and thereby leading to neointimal hyperplasia $[4,5]$. Bone marrow mesenchymal stem cells (BMSC) have a self-renewal capacity, long-term viability, and the potential to differentiate into diverse cell types, such as adipogenic, osteogenic, chondrogenic, and myogenic lineages [6-8]. In vitro, BMSC have been shown to differentiate into VSMC in response to the transforming growth factor $\beta$ (TGF- $\beta$ ) [9], mechanical stress [10], and direct contact with vascular endothelial cells [11]. Neointimal SMC has been shown to express a number of hematopoietic lineage markers $[12,13]$. Sata and colleagues showed that bone marrow is the potential source of vascular progenitors that contribute to pathological arterial remodeling in models of postangioplasty, restenosis, transplant-associated arteriosclerosis, and hyperlipidemia-induced atherosclerosis [2].

Moreover, intimal SMC in graft arterial disease can originate from recipient bone marrow cells [14]. On the other hand, there have been few studies closely following the cell differentiation of smooth muscle lineage among BMSC. Reports have shown that BMSC differentiate not only into cardiomyocytes, but also into vascular smooth muscle cells progenitors and endothelial cells. These cell types are involved in the development of vascular systems, including angiogenic sprouting and vessel enlargement. However, the biological characteristics of foam cell formation in BMSC-SMC involved in atherosclerosis are largely unknown.

Here we show that BMSC yield VSMC (BMSC-SMC), which exhibit distinct characteristics by treatment with oxidative modified low-density lipoprotein (ox-LDL), can be induced to foam cells and be involved in the development of atherosclerosis.

\section{Results}

\section{VSMC differentiated from bone marrow MSC}

TGF- $\beta$ signaling is thought to direct, in part, the differentiation of mesenchymal lineage cell types to VSMC [15]. Treating of BMSC with $2.5 \mathrm{ng} / \mathrm{ml} \beta$-FGF and $5 \mathrm{ng} / \mathrm{ml}$ TGF- $\beta$ for 15 days elicited their differentiation into VSMC, as demonstrated by their increased expression of the SMC-specific cytoskeletal protein a-SMA and the SMC-specific contractile protein, SM-MHC1 (Figure 1).

\section{Foam cell formation of BMSC-SMC and VSMC in- duced by ox-LDL}

Ox-LDL is involved in the pathogenesis of atherosclerosis. Foam cells, one of the hallmarks of atherosclerotic plaques, develop when monocyte-derived macrophages or smooth muscle cells within the arterial wall take up ox-LDL via scavenger receptors. Using Oil Red O staining, we checked the morphological change of cells after incubation of BMSC-SMC and VSMC with $80 \mathrm{mg} / \mathrm{L}$ ox-LDL for 72 hours, and we found that lipid staining became positive compared with the control group (Figure 2, Table 1). There was much more cholesterol assembled in BMSC-SMC compared with VSMC.

Table 1 Intracellular lipid content in BMSC-SMC and VSMC. Cells were treated with the $80 \mathrm{mg} / \mathrm{L}$ ox-LDL for 72 hours. Cellular lipid was extracted, and free cholesterol(FC), total cholesterol(TC) were analyzed by HPLC. CE and ratio of $\mathrm{CE} / \mathrm{TC}$ were calculated.

\begin{tabular}{lllll}
\hline Cells group & $\begin{array}{llll}\mathrm{FC}(\mu \mathrm{g} / \mathrm{m}) \\
\text { g protein })\end{array}$ & $\begin{array}{l}\mathrm{CE}(\mu \mathrm{g} / \mathrm{m} \\
\text { g protein })\end{array}$ & $\begin{array}{l}\mathrm{TC}(\mu \mathrm{g} / \mathrm{m} \\
\text { g protein })\end{array}$ & $\begin{array}{l}\mathrm{CE} / \mathrm{TC}( \\
\text { Control }\end{array}$ \\
$45.9 \pm 3.2$ & $5.3 \pm 2.6$ & $40.1 \pm 3.5$ & 13.2 \\
& & & & \\
VSMC+ox-LDL & $86.5 \pm 4.1^{*}$ & $116.6 \pm 4.5^{*}$ & $196.7 \pm 9.5^{*}$ & 59.3 \\
& & & & \\
BMSC-SMC+ox-LDL & $92.1 \pm 9.4$ & $167.6 \pm 8.9$ & $301.3 \pm 8.5$ & 55.6
\end{tabular}

* $\mathrm{P}<0.05$ vs Control

\section{Effect of ox-LDL on cell proliferation in BMSC-SMC and VSMC}

The growth curve of BMSC-SMC and VSMC represented an "S" shape. Also, the doubling times were 32 hours and 20 hours respectively. After treatment with $80 \mathrm{mg} / \mathrm{L}$ ox-LDL, the doubling times were 28 hours and 15 hours respectively (Figure 3A).

To investigate whether the ox-LDL treatment has an effect on cell cycle regulation, we assessed for cell cycle distribution by flow cytometry. As shown in Figure 3B, cells cultured for 3 days in the presence of ox-LDL resulted in an accumulation of these cells in the G0/G1 phase of the cell cycle, with a concomitant decrease in the proportion of those in S and G2/M phases. But there is no statistical significance in the cases of BMSC-SMC and VSMC.

\section{Effects of ox-LDL on cell collagen synthesis, at- tachment, and migration in BMSC-SMC and VSMC}

To determine if the protein level of the main component of extracellular matrix, i.e., collagen, is altered by ox-LDL, total collagen content was determined in BMSC-SMC and VSMC using hydroxyproline assay. As shown in Figure 4A, ox-LDL significantly reduced collagen production compared with the control group, but there is no statistical significance for BMSC-SMC and VSMC. 
To determine whether cell attachment was affected by ox-LDL, cells were seeded and allowed to attach on glass plates for time periods up to 1 hour. Incubation with ox-LDL slightly increased attachment of BMSC-SMC compared with control cells. But there is no statistical significance compared with the control group. However, incubation with ox-LDL slightly decreased attachment of VSMC compared with control group but there is no statistical significance (Figure $4 \mathrm{~B})$.
Migration of VSMC within the arterial wall is a crucial event in the remodeling and progression of atherosclerotic plaques as well as in vascular repair [16]. To determine whether ox-LDL can affect BMSC-SMC and VSMC migration, cells were treated with $80 \mathrm{mg} / \mathrm{L}$ ox-LDL for 24 hours. The result suggests that ox-LDL are effective in accelerating BMSC-SMC and VSMC migration compared with the control group $(\mathrm{P}<0.01)$. There was much more BMSC-SMC migration compared with VSMC after treatment with ox-LDL (Figure 4C).
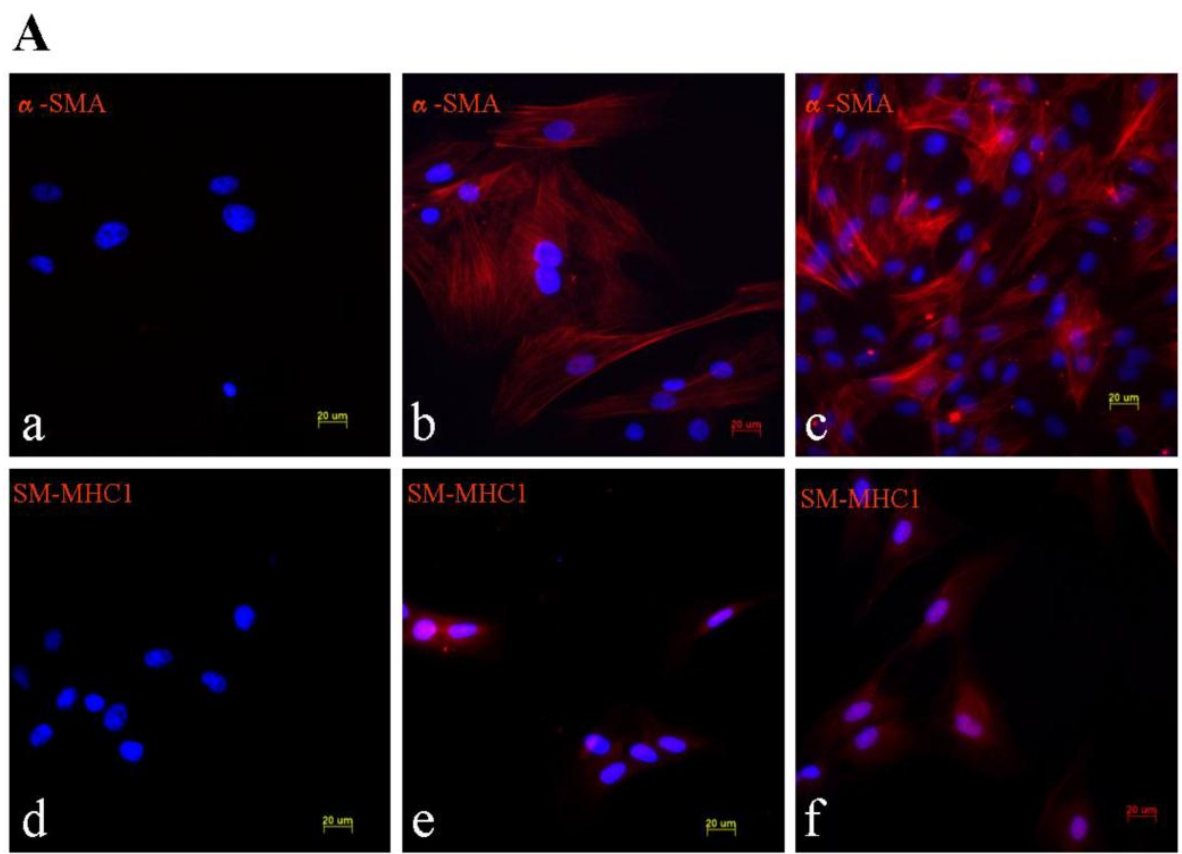

B

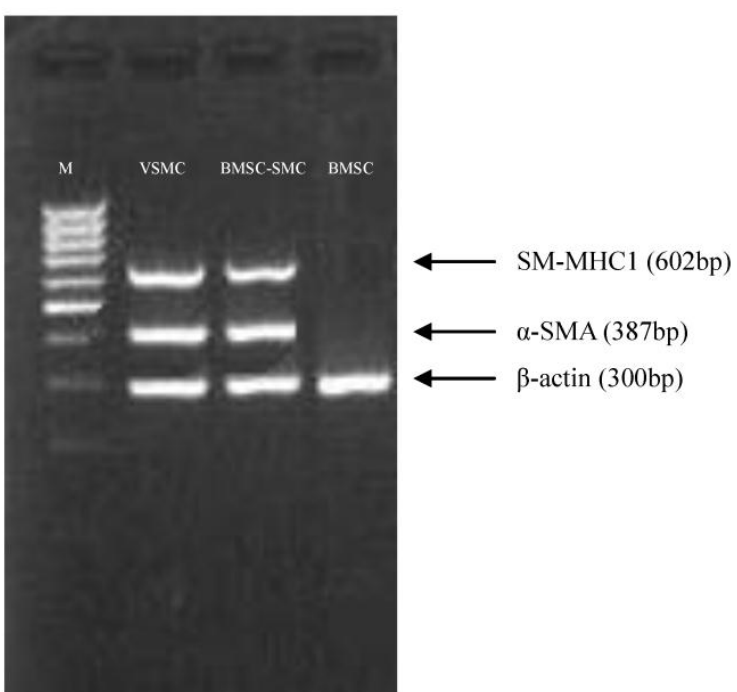

Figure 1. Phenotypic characterization of BMSC, BMSC-SMC and VSMC. Immunofluorescence analysis of a-SMA and SM-MHC1 in BMSC, BMSC-SMC and VSMC (100x). (A) The expression of a-SMA in BMSC (a), VSMC (b) and BMSC-SMC (c); the expression of SM-MHC1 in BMSC (d), VSMC (e) and BMSC-SMC (f). (B) RT-PCR analyzed the expression of a-SMC and SM-MHC1 in VSMC (line 1), BMSC-SMC (line 2) and BSMC (line 3). 

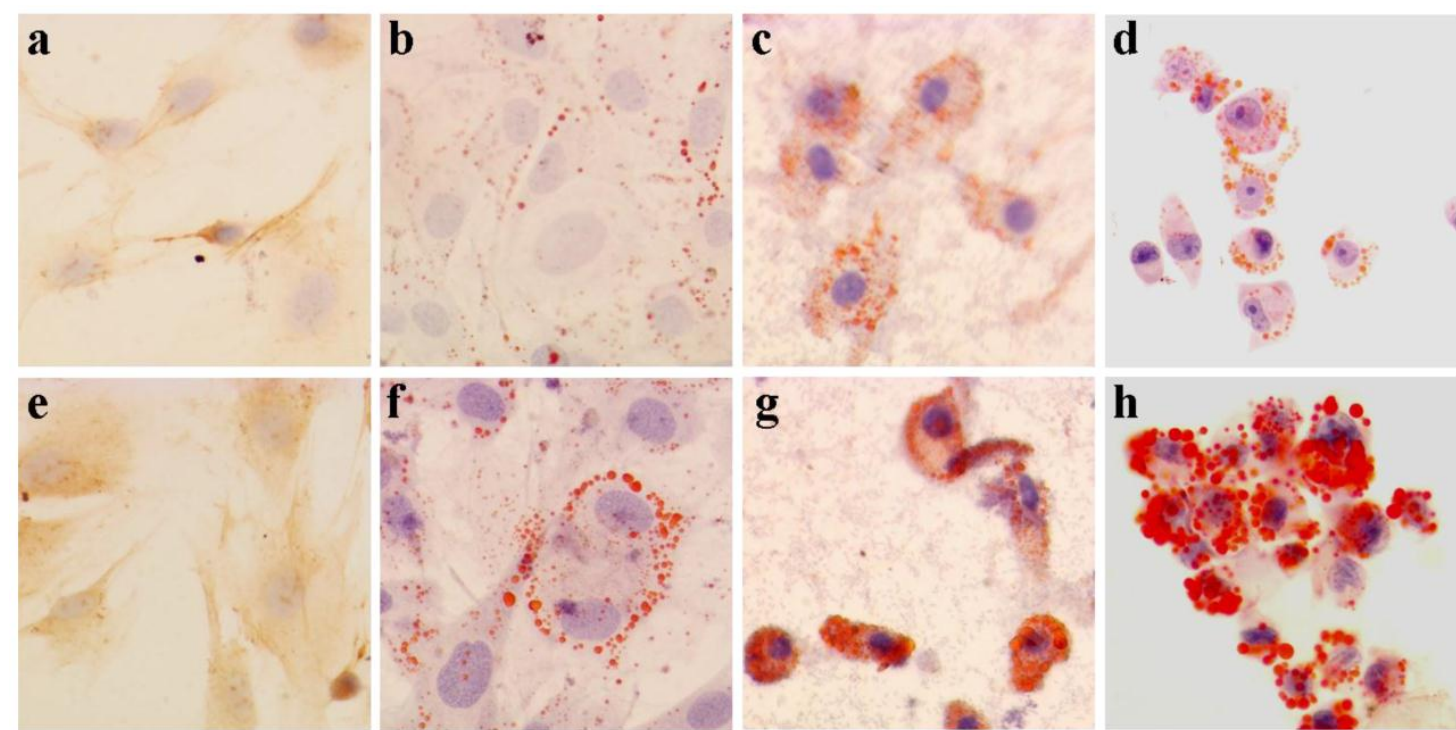

Figure 2. Ox-LDL induced foam cell formation of BMSC, VSMC, BMSC-SMC and macrophages by Oil Red 0 staining. BMSC, VSMC, BMSC-SMC and macrophases were incubated with $80 \mathrm{mg} / \mathrm{L}$ ox-LDL (e, f, g and h) and PBS (a, b, c and d) for 72 hours. The cells were harvested or fixed for Oil Red 0 staining.

A

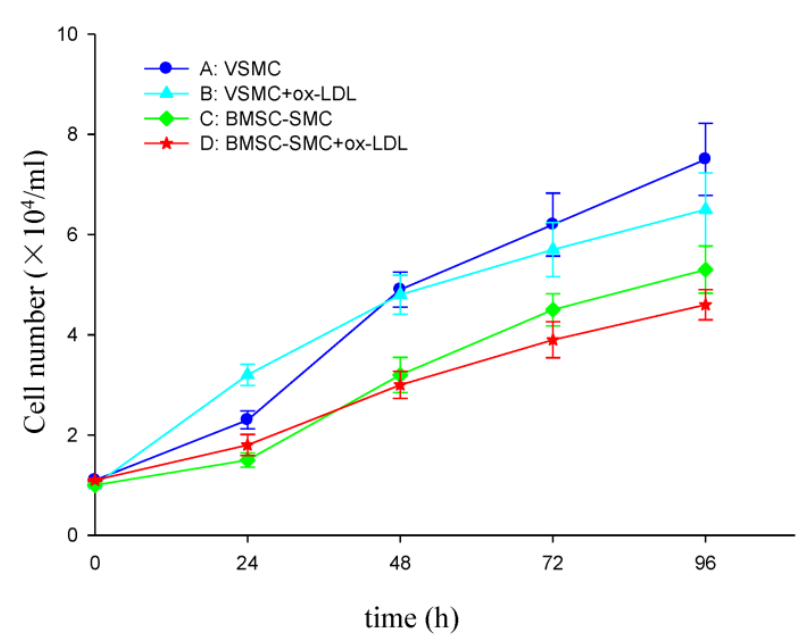

$\mathrm{B}$

a
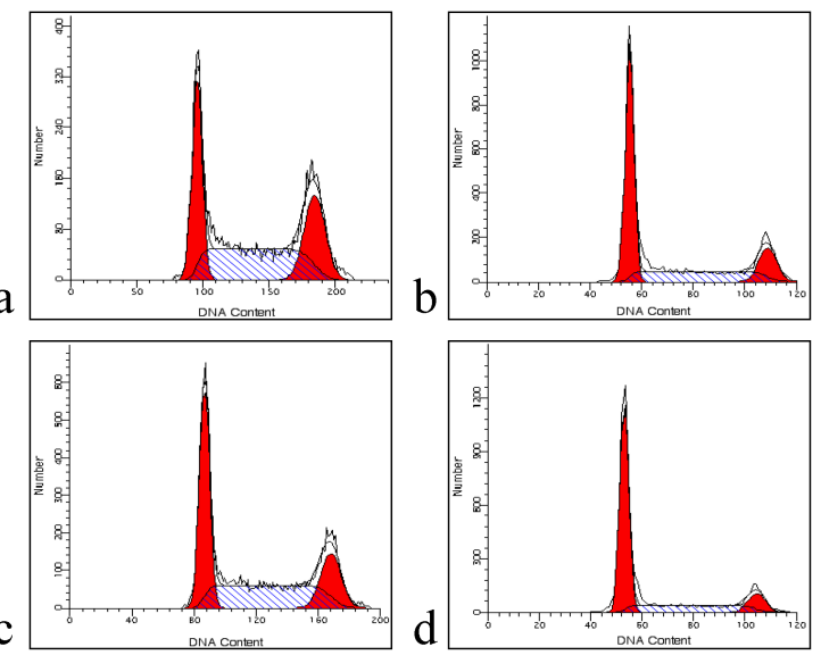

Figure 3. Effect of ox-LDL on cell proliferation in BMSC-SMC and VSMC. (A) Cell growth curves of BMSC-SMC and VSMC after treatment with $80 \mathrm{mg} / \mathrm{L}$ ox-LDL for 24, 48, 72 and $96 \mathrm{~h}$. (B) Cell cycle distribution in VSMC (b) and BMSC-SMC (d) after treated with $80 \mathrm{mg} / \mathrm{L}$ ox-LDL and PBS (a and c) for 72 hours. 


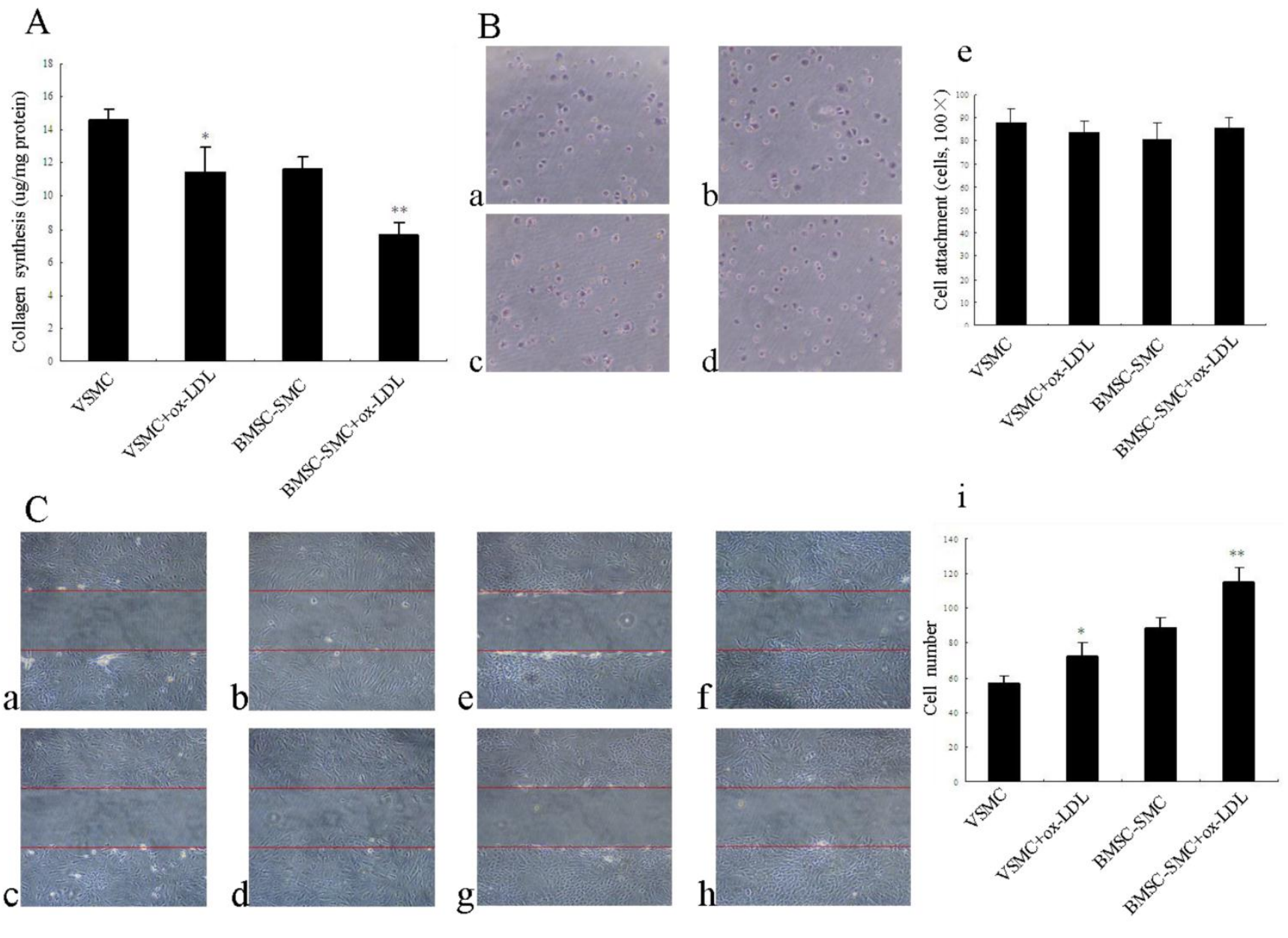

Figure 4. Effects of ox-LDL on cell collagen synthesis, attachment and migration in BMSC-SMC and VSMC. (A) Cell collagen synthesis was determined by hydroxyproline-based assays. BMSC-SMC and VSMC were treated with $80 \mathrm{mg} / \mathrm{L}$ ox-LDL for 72 hours. (B) Cell attachment was analyzed by cell adhesion assays. VSMC (b) and BMSC-SMC (d) were treated with $80 \mathrm{mg} / \mathrm{L}$ ox-LDL and PBS ( $a$ and $c$ ) for 1 hour. (C) Cell migration was detected by wound healing assays. BMSC-SMC and VSMC were treated with $80 \mathrm{mg} / \mathrm{L}$ ox-LDL or without $80 \mathrm{mg} / \mathrm{L}$ ox-LDL for 0 hour (a: BMSC-SMC + ox-LDL and c: BMSC-SMC; e: VSMC + ox-LDL and g: VSMC) and 24 hours (b: BMSC-SMC+ox-LDL and d: BMSC-SMC; f: VSMC + ox-LDL and h: VSMC). The results were obtained from at least three independent measurements. ${ }^{*} p<0.05$, ${ }^{* *} p<0.01$ compared to control.

Effects of ox-LDL on scavenger receptor class $A$, the ATP-binding cassette transporter A1 and caveolin-1 expression in BMSC-SMC and VSMC

It is postulated that ox-LDL is the ligand for the scavenger receptor on the membrane of macrophages and smooth muscle cells. LDL uptake via this pathway leads to massive accumulation of lipid and thus foam cell formation. The scavenger receptor activity is up regulated in the smooth muscle cells of atherosclerotic lesions. In this study, incubation with the $80 \mathrm{mg} / \mathrm{L}$ ox-LDL for 72 hours significantly up regulated the scavenger receptor class A (SR-A) protein expression of BMSC-SMC and VSMC compared to the control group, respectively. There was a lot more in- creased scavenger receptor class A (SR-A) protein in BMSC-SMC compared with VSMC (Figure 5A).

The ATP-binding cassette transporter A1 (ABCA1) exports excess cellular cholesterol into the HDL pathway and reduces cholesterol accumulation in macrophages. We examined the protein level of the ATP-binding cassette transporter A1 (ABCA1) in BMSC-SMC and VSMC by western blotting analysis to study whether the ATP-binding cassette transporter A1 (ABCA1) is involved in cholesterol accumulation in BMSC-SMC and if it is regulated by ox-LDL. The result demonstrated that the ATP-binding cassette transporter A1 (ABCA1) protein level was high in untreated BMSC-SMC compared with untreated VSMC, and the $80 \mathrm{mg} / \mathrm{L}$ ox-LDL sig- 
nificantly decreased ABCA1 protein level in both BMSC-SMC and VSMC (Figure 5B).

Caveolins, and especially caveolin-1, have been implicated in the regulation of cellular cholesterol metabolism and lipid uptake, as well as their efflux [17]. We examined the protein level of caveolin-1 in BMSC-SMC and VSMC by western blotting analysis to determine whether caveolin-1 is involved in lipid

\section{A}
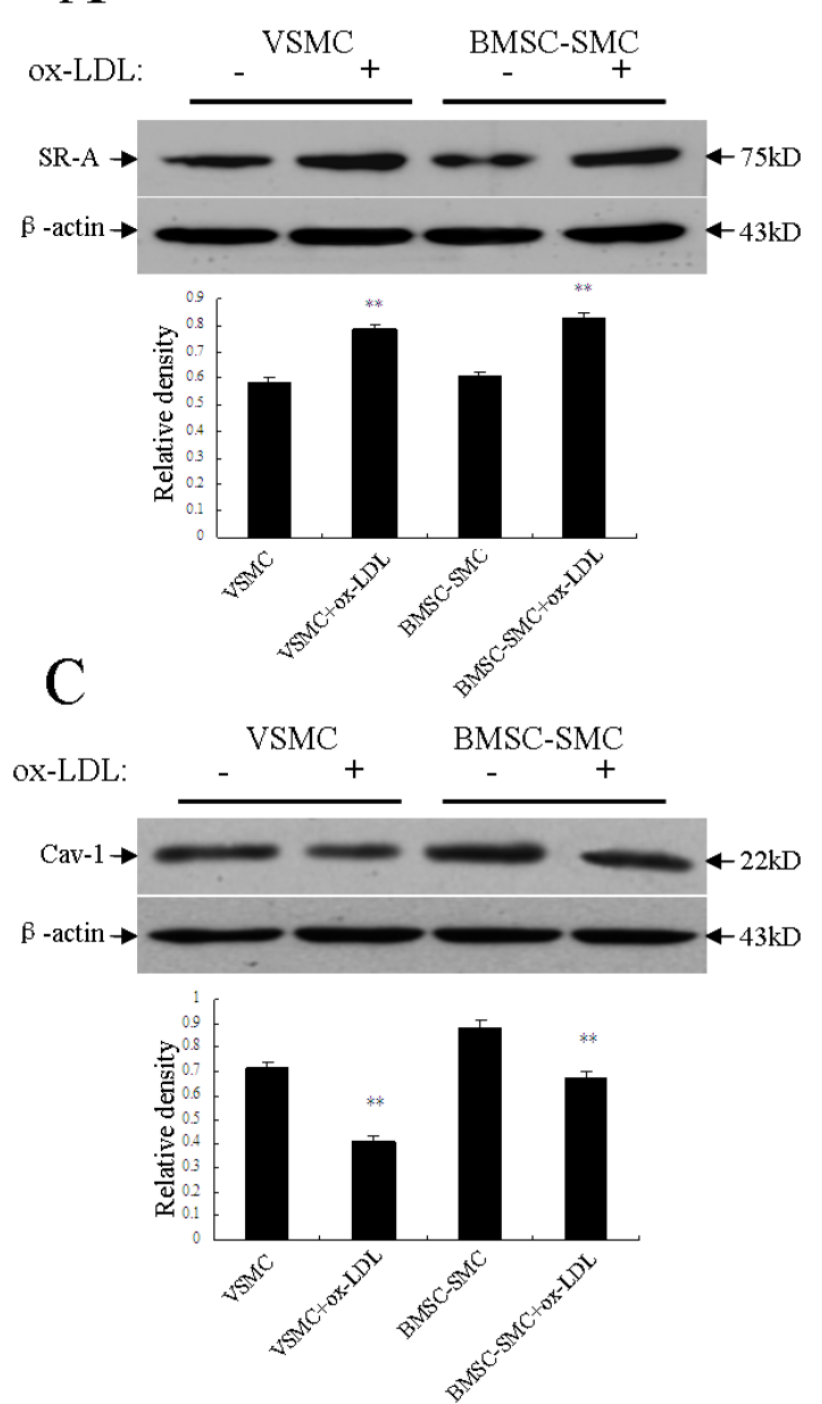

uptake in BMSC-SMC and if it is regulated by ox-LDL. The result demonstrated that caveolin-1 protein level was high in untreated BMSC-SMC compared with untreated VSMC. After treatment with the $80 \mathrm{mg} / \mathrm{L}$ ox-LDL for 72 hours, the expression of caveolin-1 was significantly decreased in both BMSC-SMC and VSMC (Figure 5C).

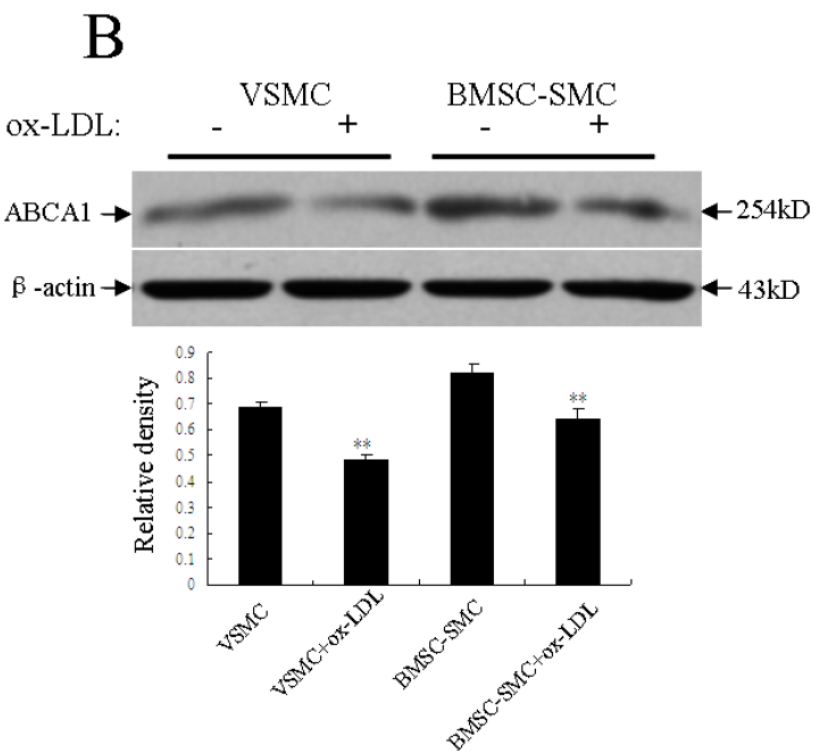

Figure 5. Effects of ox-LDL on the expression of SR-A, ABCA1 and caveolin-1 in BMSC-SMC and VSMC. BMSC-SMC and VSMC were treated with $80 \mathrm{mg} / \mathrm{L}$ ox-LDL for 72 hours. (A) the expression of SR-A; (B) the expression of ABCA1 and (C) the expression of caveolin-1. The results were obtained from at least three independent measurements. ${ }^{* *} \mathrm{p}<0.01$ compared to control.

\section{Discussion}

The process of atherosclerosis, in the beginning, is characterized by intimal thickening caused by hyperplasia of the VSMC. Recently, it has been shown that vascular progenitor cells exist inside normal vessel walls and the number is increased in atherosclerotic lesions [18]. The origin of such VSMC progenitor cells is under debate, i.e., whether these cells are derived from bone marrow or dedifferentiated 
intimal cells. This indicates, however, that there may be many possible origins of VSMC [19-21]. It was reported that blood cells contain progenitors that have the potential to differentiate into either endothelial cells or VSMC in vitro according to the composition of the culture medium [22]. BMSC are a multipotent cell type that can differentiate down the osteoblastic, chondrogenic, myogenic, or adipogenic lineages. Moreover, intimal VSMC in graft arterial disease can originate from recipient bone marrow cells [14]. In this study, we observed that BMSC could be induced into VSMC. The biology characteristics of BMSC-SMC are similar with VSMC. They also can express a-SMA and SM-MHC1, which act as molecular markers in VSMC. These cells might take part in the development of atherosclerosis.

Massive accumulation of lipid in cells leads to the formation of foam cells, a pathological feature of atherosclerosis [23, 24]. Scavenger receptors, a family of trimeric membrane glycoproteins at the surface of vascular cells, can specifically mediate the uptake of ox-LDL [25]. In normal VSMC, the expression of scavenger receptors is weak. However, in the presence of appropriate stimulation, expression of the receptor is increased. In contrast, expression of the receptor in smooth muscle cells of the aortic media did not change. These results clearly demonstrate the induction of scavenger receptor expression in smooth muscle cells of the neointima, which is the location of primordial lesions of atherosclerosis. Our findings demonstrated that the ox-LDL significantly up-regulated scavenger receptor class A (SR-A) protein expression in BMSC-SMC and VSMC compared to untreated cells. Interestingly, a greater rate of increase was found in the BMSC-SMC compared to the VSMC. The result suggested that the BMSC-SMC might be induced into foam cells by the up regulation of the SR-A protein expression.

The ATP-binding cassette transporter A1 (ABCA1) is a transporter that mediates the export of cellular cholesterol, phospholipids, and other metabolites to lipid-poor HDL apolipoproteins. Reciprocal bone marrow transplantation studies using wild type and ABCA1-null mice have shown that selectively over or under expressing the ATP-binding cassette transporter A1 in macrophages decreases or increases atherosclerosis, respectively [26]. Some studies show that the ATP-binding cassette transporter A1 is a cardioprotective factor and the reduction of the ATP-binding cassette transporter A1 activity contributes to smooth muscle foam cell formation in the intima [27].

The potential role of caveolins in the intracellular transport of cholesterol and its physical association with the cholesterol-rich rafts makes it tempting to speculate that these proteins play an important role in cholesterol metabolism of macrophages. The recently generated caveolin-1 knockout mice, confirm the importance of caveolin-1 for the formation of morphologically distinct caveolae $[28,29]$. Caveolin-1 is also involved in the maintenance of cellular cholesterol homeostasis and lipid transport. Some studies demonstrate that caveolae and caveolin-1 expression is associated with enhancement of cholesterol efflux $[30,31]$. Our present study demonstrated that the ox-LDL decreased the expressions of the ATP-binding cassette transporter A1 and caveolin-1. These results suggested that BMSC-SMC might be induced into foam cells also by down-regulation the ATP-binding cassette transporter A1 and caveolin-1 protein expression. Further research will help clarify the interaction between Caveolin-1 and the ATP-binding cassette transporter A1 in BMSC-SMC.

VSMC proliferation and migration, as well as, extracellular matrix remodeling are important events in the pathophysiological course of atherosclerosis. These events are mediated by various cytokines and growth factors and also depend on the degradation of extracellular matrix by proteinases such as matrix metalloproteinases. VSMC migrate from the medial layer of arterial wall into the intimal space and then form the neointema progressively; in addition, together with abundant level of extracellular matrix proteins, VSMC trigger the formation of atherosclerotic plaques. In our previous studies we found that the ox-LDL promoted cell proliferation and accelerated cell migration in both BMSC-SMC and VSMC [32]; however, the extent of change was more significant in the BMSC-SMC. These results indicated that BMSC-SMC could proliferate and play a role in atherosclerosis. Our findings provide the basis for the development of new therapeutic strategies for vascular diseases, by targeting mobilization, homing, differentiation and proliferation of bone marrow-derived vascular progenitor cells.

In summary, our findings indicated that bone marrow-derived smooth muscle progenitor cells might become new targets to prevent vascular diseases. We observed that BMSC could differentiate into VSMC and the BMSC-SMC could express a-SMA and SM-MHC1, which act as molecular markers in VSMC. Moreover, these BMSC-SMC could be induced into foam cells by ox-LDL. Some biological characteristics, such as foam cell formation, proliferation, migration and collagens synthesis, are similar between BMSC-SMC and VSMC, however, the extent of these characteristics change are more significant in the 
BMSC-SMC. It may act as an important factor in the pathophysiological course of atherosclerosis.

\section{Materials and Methods}

\section{Isolation and culture of bone marrow MSC}

Six-week-old male SD rats were obtained from the central animal facility of Nanhua University and were euthanized with an overdose of pentobarbital solution. Both tibias and femurs were dissected and the bone marrow was extruded in $5 \mathrm{~mL}$ of DMEM with a syringe. The cells were then plated in DMEM supplemented with $10 \% \mathrm{FBS}$ and incubated at $37^{\circ} \mathrm{C}$ in a humidified atmosphere containing $5 \% \mathrm{CO}_{2}$. Nonadherent cells were removed by replacing the medium. The medium was changed every 3 days.

\section{Isolation and culture of VSMC}

Rat aortic VSMC were isolated from thoracic aorta of six-week-old male SD rats using the explants technique [33]. Briefly, after the removal of endothelium and adventitia, the aortic explants were cultured in DMEM containing 10\% FBS. After 2 weeks, cells that migrated out of the explants were removed by trypsinization and were subcultured successively. The identity and purity of the VSMC were verified by immunostaining using antibody against a-SMA.

\section{RT-PCR}

Expression of rat a-SMA and SM-MHC1 mRNA was analyzed by the RT-PCR method. Primers for a-SMA were 5'-ACCCAGATTATGTTTGAGACC-3' (sense), 5'-CCGTCAGGCAGTTCGTAG-3' (antisense); primers for SM-MHC1 were 5'-CGGCAACTCGT GTCCAAC-3' (sense), 5'-TGCTTTCGCTCGTCTTCC $-3^{\prime}$ (antisense); primers for $\beta$-actin were 5'-GCCAACCGTGAGAAGATGAC-3' (sense), 5'-CTGTGTTGGCATAGAGGTC-3' (antisense). The annealing temperatures were $55^{\circ} \mathrm{C}$ for a-SMA and SM-MHC1. The numbers of cycles of PCR were 35 for a-SMA and SM-MHC1. $\beta$-actin was used as internal controls.

\section{Immunofluorescence}

Cells were plated on glass coverslips. After the treatment, the cells were washed with PBS. Then, cells were fixed with $4 \%$ paraformaldehyde for $10 \mathrm{~min}$. All fixed cells were permeabilised in $0.1 \%$ Triton X-100 for $10 \mathrm{~min}$. The cells were incubated with a-SMA or SM-MHC1 antibody for $60 \mathrm{~min}$ at room temperature. Then the cells were incubated with the secondary antibody, rhodamine-conjugated anti-rabbit IgG (Amersham Life Sciences) for $30 \mathrm{~min}$. Coverslips were mounted and analyzed by fluorescent microscopy.

\section{LDL isolation and oxidization}

LDL was separated from freshly normal human plasma by sequential ultracentrifugation, as described previously [34]. In brief, the obtained LDL were extensively dialyzed at $4^{\circ} \mathrm{C}$ against $0.15 \mathrm{~mol} / \mathrm{L} \mathrm{NaCl}$ and $0.01 \%$ EDTA (pH 8.0) and quantified by Bradford kit (Bio-Rad, Hercules, CA). After the EDTA was removed, LDL was oxidized by exposure to $5 \mathrm{mmol} / \mathrm{L}$ $\mathrm{CuSO}_{4}$ for 24 hours at $37^{\circ} \mathrm{C}$. Then the $\mathrm{Cu}^{2+}$ was removed by extensive dialysis.

\section{Foam cell formation}

BMSC-SMC or VSMC were cultured in DMEM with $10 \%$ FBS for 24 hours and treated with or without the $80 \mathrm{mg} / \mathrm{L}$ ox-LDL for an additional 72 hours. The cells were harvested or fixed for Oil Red O staining or for HPLC.

\section{Lipid analysis by HPLC}

Cellular lipid (TC, FC and cholesterol ester [CE]) contents were analyzed by our method described previously [35]. Briefly, cells were washed by PBS in 3 times and lysated by $0.1 \mathrm{~N} \mathrm{NaOH}$ solution and homogenized on ice for 10 seconds by ultrasound. Proteins concentration was measured by using of BCA kit. Then an equal volume of trichloroacetic acid was added and centrifuged at $800 \mathrm{~g}$ for $10 \mathrm{~min}$. Use Stigmasterol to do standard curve first and repeat the extraction procedure. The organic phase was transferred to clear glass tubes, and dried a vacuum. The samples were dissolved in $100 \mu \mathrm{l}$ isopropanol-acetonitrile (v/v, 20:80), followed by an ultrasound water bath at room temperature for 5 minutes. Finally, the samples were subjected to HPLC analysis (Agilent 1100, Agilent Technology, USA), Cholesterol was eluted with isopropanol-acetonitrile solution (v/v, 20:80) at the speed of $1 \mathrm{ml} /$ minute, C-18 column; $4^{\circ} \mathrm{C}$ and detected by $206 \mathrm{~nm}$ UV absorption.

\section{Cell growth experiments}

Cells were harvested from 24 well plates by centrifugation at $1000 \mathrm{rpm}$ for $5 \mathrm{~min}$. Each pellet was resuspended in 1:1 mixture of $2 \%$ trypan blue dye and PBS. Cells were loaded onto the hemocytometer and counted. The mean and standard deviation were calculated for each time point. On days 1, 2 and 3 after the addition of treatment medium, cells were trypsinized and counted using a hemocytometer. All counts were obtained in duplicate at each time point.

\section{DNA cell cycle analysis by flow cytometry}

After treatment of cells with the $80 \mathrm{mg} / \mathrm{L}$ ox-LDL for 72 hours, floated cells were discarded by aspiration and the attached cells were trypsinized and 
fixed with ice-cold $70 \%$ ethanol for 1 hour. The cells were resuspended in $1 \mathrm{ml}$ RNase $(1 \mathrm{mg} / \mathrm{ml})$ for 30 min, centrifuged and resuspended in $0.5 \mathrm{ml}$ propidium iodide (PI, $50 \mu \mathrm{g} / \mathrm{ml}$ ) for $30 \mathrm{~min}$ at room temperature. The flow cytometric analysis was performed on a BD flow cytometer.

\section{Collagen synthesis}

To test the total collagen production, cells were seeded in six well culture plates and grown until confluent in DMEM with 10\% FBS. Cells were starved for 24 hours before the addition of the ox-LDL. After 72 hours of treatment, cells were scraped on the cell culture medium of six well culture plates. Both the cell lysate and culture medium were removed and placed in test tubes, and net collagen production was determined with a hydroxyproline-based assay as described previously [36].

\section{Cell attachment assay}

Six well culture plates were coated with fibronectin for 24 hours at $4^{\circ} \mathrm{C}$. For all assays, cells were seeded at a density of $1.0 \times 10^{5} / \mathrm{ml}$ into six well culture plates with and without the $80 \mathrm{mg} / \mathrm{L}$ ox-LDL. After 1 hour, the non-adherent cells were removed by washing with PBS and attached cells were fixed with $4 \%$ paraformaldehyde. Attachment was assessed by counting the number of cells in five independent high-power fields at $100 \times$ magnification.

\section{Cell migration assay}

BMSC-SMC and VSMC were seeded at a density of $1.0 \times 10^{5} / \mathrm{ml}$ into six well culture plates and incubated at $37^{\circ} \mathrm{C}$ for 48 hours. A cotton swab was used to wound the monolayer and denude two areas in each well of cells. Then cells were treated with and without the $80 \mathrm{mg} / \mathrm{L}$ ox-LDL for 24 hours. Migration was evaluated by quantitating migration of cells into the denuded areas of the cultures. Results are reported as means \pm SE of five different fields, from three experiments, counted at $200 \times$ magnification.

\section{Western blot analysis}

Following specified treatments, BMSC-SMC and VSMC were washed twice with ice-cold PBS and harvested in sample buffer. Soluble extracts were prepared by centrifugation at $12000 \mathrm{~g}$ for $30 \mathrm{~min}$ at $4^{\circ} \mathrm{C}$. Protein concentration was determined using the BCA kit (Pierce Chemical Co, Rockford, IL). Equivalent amounts of protein $(40 \mu \mathrm{g})$ for each sample were resolved in SDS-PAGE. After electrophoresis, proteins were transferred to nitrocellulose membranes. Membranes were incubated in TBST containing 5\% nonfat milk for 1 hour at room temperature. The blots were then reacted with primary antibody overnight at $4^{\circ} \mathrm{C}$. Antibodies used for western blot analysis included caveolin-1, scavenger receptor class $A$, the ATP-binding cassette transporter A1, and $\beta$-actin antibody (Sigma). After washing with TBST, the membrane was then incubated with the corresponding horseradish peroxidase conjugated secondary antibodies (Cell signaling). The signals were visualized by ECL (Pierce Chemical Co.) and then exposed to X-ray films.

\section{Statistical Analysis}

Data are expressed as mean \pm SEM. The statistical significance of differences was assessed by Student's $t$ tests or ANOVA, as appropriate; a value of $P<0.05$ was considered statistically significant.

\section{Acknowledgments}

This work was supported by Hunan Provincial Science and Technology Department Fund (200606), Guangdong Provincial Health Department Fund (200884), Guangdong Provincial Traditional Chinese Medicine Administration Fund to Y.P.

\section{Conflict of Interests}

The authors have declared that no conflict of interest exists.

\section{References}

1. Tabas I. Macrophage death and defective inflammation resolution in atherosclerosis. Nat Rev Immunol. 2010;10(1):36-46.

2. Sata M, Saiura A, Kunisato A, et al. Hematopoietic stem cells differentiate into vascular cells that participate in the pathogenesis of atherosclerosis. Nat Med. 2002;8(4):403-409.

3. Borissoff JI, Spronk HM, ten Cate H. The hemostatic system as a modulator of atherosclerosis. $N$ Engl J Med. 2011;364(18):1746-1760.

4. Cheong A, Li J, Sukumar P, et al. Potent suppression of vascular smooth muscle cell migration and human neointimal hyperplasia by KV1.3 channel blockers. Cardiovasc Res. 2011;89(2):282-289.

5. Charo IF, Taub R. Anti-inflammatory therapeutics for the treatment of atherosclerosis. Nat Rev Drug Discov. 2011;10(5):365-376.

6. Barry FP, Murphy JM. Mesenchymal stem cells: clinical applications and biological characterization. Int J Biochem Cell Biol 2004; 36:568-584.

7. Baksh D, Yao R, Tuan RS, et al. Comparison of proliferative and multilineage differentiation potential of human mesenchymal stem cells derived from umbilical cord and bone marrow. Stem Cells. 2007;25(6):1384-1392.

8. Zhang F, Tsai S, Kato K, et al. Transforming growth factor-beta promotes recruitment of bone marrow cells and bone marrow-derived mesenchymal stem cells through stimulation of MCP-1 production in vascular smooth muscle cells. J Biol Chem 2009; 284:17564-17574.

9. Yamazaki S, Iwama A, Takayanagi S, et al. TGF-beta as a candidate bone marrow niche signal to induce hematopoietic stem cell hibernation. Blood. 2009;113(6):1250-1256. 
10. Ishijima $\mathrm{M}$, Tsuji $\mathrm{K}$, Rittling SR, et al. Osteopontin is required for mechanical stress-dependent signals to bone marrow cells. J Endocrinol. 2007;193(2):235-243.

11. Maltais S, Perrault LP, Ly HQ. The bone marrow-cardiac axis: role of endothelial progenitor cells in heart failure. Eur J Cardiothorac Surg. 2011;39(3):368-374.

12. Fadini GP, Tjwa M, et al. A role for TGF-beta in transforming endothelial progenitor cells into neointimal smooth muscle cells. Atherosclerosis. 2010 ;211(1):32-35.

13. Kim HJ, Yoo EK, Kim JY, et al. Protective role of clusterin/apolipoprotein J against neointimal hyperplasia via antiproliferative effect on vascular smooth muscle cells and cytoprotective effect on endothelial cells. Arterioscler Thromb Vasc Biol. 2009;29(10):1558-1564.

14. Shimizu K, Sugiyama S, Aikawa M, et al. Host bone-marrow cells are a source of donor intimal smooth- muscle-like cells in murine aortic transplant arteriopathy. Nat Med 2001; 7:738-741.

15. Chen S, Lechleider RJ. Transforming growth factor-beta-induced differentiation of smooth muscle from a neural crest stem cell line. Circ Res. 2004;94(9):1195-1202.

16. Azari BM, Marmur JD, Salifu MO et al. Silencing of the F11R gene reveals a role for F11R/JAM-A in the migration of inflamed vascular smooth muscle cells and in atherosclerosis. Atherosclerosis. 2010;212(1):197-205.

17. Frank PG. Endothelial caveolae and caveolin-1 as key regulators of atherosclerosis. Am J Pathol. 2010;177(2):544-546.

18. Hristov M, Zernecke A, Schober A, et al. Adult progenitor cells in vascular remodeling during atherosclerosis. Biol Chem. 2008;389(7):837-844.

19. Roberts N, Jahangiri M, Xu Q. Progenitor cells in vascular disease. J Cell Mol Med 2005; 9:583-591.

20. Majesky MW. Developmental basis of vascular smooth muscle diversity. Arterioscler Thromb Vasc Biol 2007; 27:1248-1258.

21. Medbury HJ, Tarran SL, Guiffre AK, et al. Monocytes contribute to the atherosclerotic cap by transformation into fibrocytes. Int Angiol 2008; 27:114-123.

22. Kaushal S, Amiel GE, Guleserian KJ, et al. Functional small-diameter neovessels created using endothelial progenitor cells expanded ex vivo. Nat Med 2001; 7:1035-1040.

23. Tian L, Luo N, Klein RL, et al. Adiponectin reduces lipid accumulation in macrophage foam cells. Atherosclerosis. 2009; 202(1):152-161.

24. Ho HH, Hsu LS, Chan KC, et al. Extract from the leaf of nucifera reduced the development of atherosclerosis via inhibition of vascular smooth muscle cell proliferation and migration. Food Chem Toxicol 2010; 48:159-168.

25. Silverstein RL, Li W, Park YM, et al. Mechanisms of cell signaling by the scavenger receptor CD36: implications in atherosclerosis and thrombosis. Trans Am Clin Climatol Assoc. 2010;121: 206-220.

26. Van Eck M, Singaraja RR, Ye D, et al. Macrophage ATP-binding cassette transporter A1 overexpression inhibits atherosclerotic lesion progression in low-density lipoprotein receptor knockout mice. Arterioscler Thromb Vasc Biol 2006; 26:929-934.

27. Choi HY, Rahmani M, Wong BW, et al. ATP-binding cassette transporter A1 expression and apolipoprotein A-I binding are impaired in intima-type arterial smooth muscle cells. Circulation 2009; 119:3223-3231.

28. Chang SH, Feng D, Nagy JA, et al. Vascular permeability and pathological angiogenesis in caveolin-1-null mice. Am J Pathol. 2009;175(4):1768-1776.

29. Drab M, Verkade P, Elger M, et al. Loss of caveolae, vascular dysfunction, and pulmonary defects in caveolin-1 gene-disrupted mice. Science 2001; 293:2449-2452.

30. Hu Q, Zhang XJ, Liu CX, et al. PPARgamma1-induced caveolin-1 enhances cholesterol efflux and attenuates atherosclerosis in apolipoprotein E-deficient mice. J Vasc Res. 2010;47(1):69-79.
31. Truong TQ, Aubin D, Falstrault L, et al. SR-BI, CD36, and caveolin-1 contribute positively to cholesterol efflux in hepatic cells. Biol Chem. 2008;389(7):837-844.

32. Yan PK, Duan CW, Li SH, et al. Effect of oxidative low-density lipoprotein on the proliferation of bone marrow stem cell-derived smooth muscle cells. Nan Fang Yi Ke Da Xue Xue Bao 2010; 30(5):989-992.

33. Keramati AR, Singh R, Lin A, Faramarzi S, et al. Wild-type LRP6 inhibits, whereas atherosclerosis-linked LRP6R611C increases PDGF-dependent vascular smooth muscle cell proliferation. Proc Natl Acad Sci U S A. 2011;108(5):1914-1918.

34. Luo DX, Xia CL, Li JM, et al. Static pressure accelerates ox-LDL-induced cholesterol accumulation via SREBP-1-mediated caveolin-1 downregulation in cultured vascular smooth muscle cells. Biochem Biophys Res Commun. 2010;403(1):52-58.

35. Yuan HY, Kuang SY, Zheng X et al. Curcumin inhibits cellular cholesterol accumulation by regulating SREBP-1/caveolin-1 signaling pathway in vascular smooth muscle cells. Acta Pharmacol Sin. 2008; 29:555-563.

36. Wang B, Omar A, Angelovska T, et al. Regulation of collagen synthesis by inhibitory Smad7 in cardiac myofibroblasts. Am J Physiol Heart Circ Physiol 2007; 293:H1282-1290. 